\title{
Assessing Speaking Ability in Academic Context for Fourth Year Taif University Students
}

\author{
Sawsan Ahmed ${ }^{1} \&$ Abdulamir Alamin ${ }^{1}$ \\ ${ }^{1}$ Taif University, Saudi Arabia \\ Correspondence: Sawsan Ahmed, Taif University, Saudi Arabia. E-mail: sawsan1930ahmed@gmail.com
}

Received: October 17, 2014 Accepted: November 11, 2014 Online Published: November 25, 2014

doi:10.5539/ijel.v4n6p97

URL: http://dx.doi.org/10.5539/ijel.v4n6p97

\begin{abstract}
The speaking skill is an important part of the curriculum in language teaching, and this makes it an important object of assessment. This study is based on a qualitative method of research where a description is produced about the quality of the speech production of the candidates. The purpose is to examine whether learners use features of that indicates advanced knowledge of English in their production. For this purpose, forty-seven university students, who were fourth-year majoring in English literature, who are taking the subject "Preparation for International Test" took an interview for their oral production final exam. After the analysis, the results will show the degree of proficiency the students are at as far as their speech production. The results will also reveal if there is statistically significant difference between the students regarding their proficiency levels and frequency of appropriate use of spoken features. Then immediate implications drawn from the results obtained in this study can help sheds light on using curriculum designed to enhance learners' speaking skills in the future.
\end{abstract}

Keywords: Oral proficiency, oral language assessment, oral language instruction, EFL speaking skills

\section{Literature Review}

The ability to speak in a foreign language is of great importance when it comes to language efficiency. The ability to reason and express our thoughts is reflected in our spoken performance. Speaking is also the most difficult language skill to assess reliably. A person's speaking ability is usually judged during a face-to-face interaction, in real time, between an interlocutor and a candidate. The assessor has to make instantaneous judgments about a range of aspects of what is being said, as it is being said. This means that the assessment might depend not only upon which particular features of speech (e.g., pronunciation, accuracy, fluency) the interlocutor pays attention to at any point in time, but upon a host of other factors such as the language level, gender, and status of the interlocutor and the personal characteristics of the interlocutor. Moreover the nature of the interaction, the sorts of tasks that are presented to the examinee, the questions asked will have an impact on the performance. Therefore, assessing speaking is not an impossible task, but it is difficult (Luoma, 2004).

Speaking in a second language has been considered the most challenging of the four skills because it is productive skill that involves a complex process of constructing meaning (Celce-Murcia \& Olshtain, 2000). It is also the most complex skill because of the simultaneous monitoring and planning of utterances. This process requires speakers to make decisions about why, how and when to communicate depending on the cultural and social context in which the speaking act occurs (Burns \& Seidlhofer, 2002).

Reading aloud is a common way of developing this skill in addition to tests using visual material as stimuli are common test procedures for testing speaking. Other activities for testing speaking include oral interviews, group or pair role play tests. The difficulty of testing the speaking skill is a well known fact by language educators. However, one of the great difficulties in testing speaking is the assessment itself and the scoring process. The speaking tasks is preferably recorded and the scoring done from the tape. Aspects of speaking that might be considered in the assessment scale are grammar, pronunciation, fluency, and content.

\section{Background}

One of the primary objectives of teaching oral communication is enhancing students' ability to use oral language in various contexts. Speaking is often interactive, involving more than one person at the same time. It can be monologic, involving one speaker. The social aspect of the skill cannot be denied as it makes the level of student' 
performance vary. A wide range of verbal skills are displayed by students such as maintaining a dialogue or participating in interview tests. (Brown, 2003; Bonk, 2003).

\subsection{Speaking and Spoken Interaction}

Teaching and testing experts often talk about speaking as a technical term to refer to one of the various skills that language learners should develop and have. This type of speaking tends to be seen as something that individuals do. It is useful for educational purposes, to view speaking in this way, because the most important part of language use is personal. Nevertheless, it is also important to remember that speaking forms a part of the shared social activity of talking.

\subsubsection{Speaking Assessment}

Testing oral proficiency has become one of the most important issues in language testing since the role of speaking ability has become more central in language teaching (Hartley \& Sporing, 1999). There are three characteristics that distinguish performance assessments from other types of tests. They are focused mainly on content. However, testing speaking is difficult and cannot be assessed as precisely and without difficulty as other language skills. It takes considerable time, effort and training (Hughes, 2003). Despite the difficulty of evaluating speaking tests, they should be designed, and administered regardless of how costly they might be.

Freed (1995) and Fulcher (1996) refer to how fluent the speaker is can be used in a range of senses. One of the narrowest definitions include a few features, such as pausing, hesitations and speech production rate, whereas in a broad sense the reference is made to speaking proficiency. Unless the term is defined explicitly, it is simply not clear what a speaker or writer means by it.

Definitions of fluency often include references to flow or smoothness, rate of speech, lack of unnecessary pausing, absence of distressing hesitation, length of utterances, and connectedness (Koponen, 1995). These characterizations are complex, however, because they are not simply descriptions of a speaker's speech but also of a listener's perception of it.

One central part of fluency is related to temporal aspects of speech, such as speaking rate, speech-pause relationships, and frequency. Both kinds of studies indicate that when speakers become more fluent their speech rate increases and the speech flow contains fewer pauses and hesitations (Lennon, 1990; Freed, 1995). They also pause at semantically sensible places, which listeners perceive as the speakers' planning the content of what they are saying rather than groping for words. More fluent speakers tend to speak more and their phrases are longer (Luoma, 2004).

In addition to time-bound speed and pausing phenomena, fluency is related to the way that speakers use words, and in particular 'smallwords' such as really, I mean, and oh (Hasselgren, 1998). To focus on the more lexical aspects of fluency, Hasselgren (1998) defined it as 'the ability to contribute to what a listener, proficient in the language, would normally perceive as coherent speech, which can be understood without undue strain, and is carried out at a comfortable pace, not being disjointed or disrupted by excessive hesitation' (p. 155). She suggested that small words are significant in this because they help speakers produce relevant turns and understand the relevance of other speakers' contributions. She summarizes the tasks of small words in the following list:

1) They express the communicative intention of the speaker, with respect to what is to be communicated and how it affects the interactional roles of the participants.

2) They point to the textual context in which an utterance has relevance.

3) They indicate the cognitive effect of the previous utterance

4) They enrich the explicature of an utterance, notably by indicating degree of commitment and vagueness.

5) They indicate the state of success of the communication, acknowledging this, or appealing for confirmation, or assistance in bringing it about.

\subsubsection{Pragmatic Skills}

Since the rise of the communicative approach to language learning in the 1970s, learners' ability to use a language has been a central focus of attention. However, many of the early studies of SLA focused on learner's acquisition of syntax rather than pragmatics (Kasper, 1996). When studies on interlanguage pragmatics began to appear in the late 1980s and 1990s, most of them focused on differences between learners and native speakers rather than the development of pragmatic skills. Recently, initiatives by Kasper (1996), House (1996) and Bardovi-Harlig (1999) have begun to change this, and the early findings suggest that it is possible to distinguish and describe varying 
levels of control of pragmatic skills. Rather than using scales for something called 'pragmatic skills', it is more common for speaking assessments to focus on areas of it.

\subsection{Learner Grammar}

Almost all speaking criteria make some reference to grammar, either as a part of holistic descriptors or in a separate analytic rating criterion. Research also indicates that raters tend to pay a lot of attention to grammar even if the test uses several analytic criteria (Brown, 2000; McNamara, 1996).

Much of the work on common learning orders in SLA has focused on grammar. While explained by nature or nurture, and whether early language learning is qualitatively different from the learning of languages later in life, most recent theories propose that people's language learning is usage-based. Ultimately, all language learning can be explained by the frequency with which we hear and see different patterns in language-use. Ellis (2002), summarizes studies from a wide range of areas including phonology, reading, spelling, lexis, and formulaic language, which show that the more exposure learners have had to patterns in these areas, the better they knowledge they have of them. His approach suggests that the process resulting in language learning is universal, but also suggests that there is natural variation in individual language users' proficiencies due to their different experiences of language use (Luoma, 2004).

\subsection{Vocabulary Command}

There are three aspects that the spoken words can have an impact on the rating scale. Many rating scales for speaking include descriptions the kind of vocabulary used by the speakers. The first is having sufficient vocabulary which often imply that the speaker is able to express his or herself precisely by displaying evidence of the richness of his or hers lexicon. Quality in addition to quantity of the vocabulary can be important in professional testing contexts particularly when the intention is to convey information. Words that are described as simple or ordinary in conjunction with fluency can also contribute to normal spoken discourse. Using those in abundance is an indicator of high speech quality. Secondly, well-chosen phrases can make descriptions vibrant where learners can evoke the listener's feelings. Thirdly, the use of the prefabricated chunks of language or formulaic phrases where the learner learns as whole can contribute to advanced speaking outcome in tests.

\section{Purpose and Research Questions}

The Purpose of this study is to investigate whether the University level learners maintain a natural fluency in their speech production. A process that is it is correlated with their language proficiency.

In the view of the facts stated above, the research questions addressed in this study are as follows:

1) Do University level learners maintain a natural flow of speech?

2) Is there any correlation between the participants' use of spoken features with the known features of language proficiency?

\section{Method}

\subsection{Participants}

Forty-seven female University level students, who were forth-year English, majoring in literature at Taif University, participated in the interview for their oral production in the final exam. There were reasons indicated by the students as to why they are keen to participate in this test. Firstly, they were highly motivated for the interview test since the score was for their finals. Secondly, they were keen to find out their level as far as the speaking skill is concerned. They further indicated that they know that the most obvious approach to oral testing and the one presumed to be the most valid is the oral interview. Thirdly, they wanted the feedback and the assurance. The interview provides a very direct method of challenging someone to speak; it also offers a realistic situation in which to assess an overall oral mastery of a particular language (Oller, 1977).

\subsection{Materials and Procedures}

This study is conducted using a qualitative method. The students who participated in an interview with the researcher are scored in a test similar to the speaking component of ILETS. In order to assess the participants' general speaking ability, a version similar to the test given for the IELTS interview tests (2007) has been utilized at the end of the term as an extension to the students' oral production of the final exam for the first term of 2013 session. The participants are assessed on their use of spoken English to answer short questions, speak at length on a familiar topic and also to ask questions and interact with the examiner. All of the procedures used are similar to the procedures suggested by IELTS, such as introduction, dialogue, discussion and conclusion. The students however are asked to pick the topics of discussion that is the only point of departure from the IELTS procedure. 
Results are scored on a nine-band scale. This band consists of five levels ranging from zero to five which represent native like ability to communicate in spoken English. However the actual score is based on a simplified scale similar to the matrix suggested by Luoma (2004) and it is as follows: Adequacy of participation: (Maintenance of interaction, initiative expansiveness) Quality of ideas: (Maturity and quality of thoughts) Interpersonal skills: (Engagement and rapport, Non-verbal behavior,) Coherence and expression: (Clarity of ideas):Linguistic criteria: (Range of strong featured vocabulary, Breadth and precision of expression) Production: (Pronunciation, Intonation, stress, and rhythm).

As indicated in the introduction, speaking tests are individually administered tests conducted by the researcher and audiotaped with permission of the students. It takes 11-14 minutes and consists of three parts Part 1: Interview (4-5 minutes) the student answers questions about herself and other familiar topic areas. During this part the questions are straight forward mostly a yes, no question or a one or two-word answer questions. Part 2: consists of (3-4 minutes) after some preparation time, the student speaks for 1-2 minutes on a topic given by the researcher. Part 3: Discussion (4-5 minutes) the researcher and student discuss more abstract issues and concepts related to the Part 2 topic.

\subsection{The List of Questions Students Are Asked During the Speaking Test}

YOU

Describe yourself.

\section{FAMILY}

Describe your family?

Do you have a large or small family?

\section{TRAVEL}

Do you like to travel?

What kind of places have you visited in your life?

Which place would you really like to visit? Why?

What's the best place you've ever visited?

\section{FRIEND}

Describe a friend.

How long have you known each other?

What do usually do together?

What do you like the most about him / her?

How often do you see each other?

\section{A GIFT YOU HAVE RECEIVED}

Describe the gift

Who gave it to you?

Why is it significant?

Their interviews are tape-recorded and then transcribed. The purpose is to examine whether the learners use features of language that indicate fluency in their natural speech production, Natural language use is also correlated with their language proficiency. Students are marked and the numbers gained for each of the items are counted. The frequency of items related to native-like features whether it is pitch, pronunciation, strategic stoppages, or the use of vocabulary reminiscent of native speakers' use is then interpreted whereby the level is measured. According to the results obtained the rate of fluency is measured for each student.

\section{Samples of Produced Erroneous Texts}

Throughout the test the students produced structures that are ranging from erroneous to basic to what can be described as native-like ones. Here are some samples: erroneous:

"I have nine families"

"She has a nice *smell" meaning smile.

"I received it in my birthday" 
"I was interest in this gift"

"Some are not for buy anymore"

"Explain you my family"

"Give me advices"

5.1 Sample of Native-Like Produced Texts

"It is kind $a$ unique" contracted form of kind of.

"A great number of them 'r close acquaintances" Use of contracted verbs.

"Trees" Use if the sound /jri/.

"What you get" Use of the sound /wjugt/

\subsection{Some Featured Transcriptions Taken from the Spoken Tests}

Here are some texts extracted from the students' speaking test. Hesitations and false starts are not included.

"I choose to talk about my mother. She is not very big. She is not very tall. Her weight is light. She has black hair. She wears nice clothes. Her age is 60. I love my mother. She is always kind to me and my brothers and sisters". In the produced text the student did not go beyond the physical description as well as the choice of vocabulary could have been better. The third feature is that the description itself is overly simplistic.

"I can speak about my father. My father was our best supporter, I mean for me and my family. When anyone needs help, we ask him first for help. He is the one who gives us gifts on our birthdays and when we pass our exams with good grades. When we do bad things, he always forgives us" Here the student has shown some creativity as far as concentrating on the emotional aspects of the person rather than just appearance.

"One of the best gifts I received is a bottle of perfume. The gift was for my graduation from high school. It was given to me by my mother. She made it as a surprise for me. She* hide it in my bag of school books and I found it on the last day of school. I was putting my books away when I found the box". The sentences in this sample are choppy. They could be connected in a better way to make the story more interesting.

\section{Findings and Discussion}

Statistically there was no significance among the students in terms of the level as most of them scored as upper intermediate. Because the assessment is done to assess the program curriculum and not to assess the students' personal development, the total number for maximum scores to the minimum scores and their standard deviation is provided.

Table 1. Mean of maximum to minimum scores of speaking assessment $(\mathrm{N}=47)$

\begin{tabular}{lll}
\hline Rate of scoring & Maximum scores & Mean SD \\
\hline a. Students who scored 5 on 50\% of the categories & 3.86 & 0.89 \\
b. Students who scored 4 on 50 \% of the categories & 3.85 & 0.94 \\
c. Students who scored 3 on all categories & 3.73 & 1.12 \\
d. Students who scored 2 on all categories & 3.5 & 1.17 \\
e. Students who scored 1 on all categories & 2.96 & 1.02 \\
f. Students who scored 1 on 50 \% of the categories & 2.68 & 1.29 \\
g. Students who scored 0 on 50\% of the categories & 2.53 & 0.81 \\
\hline
\end{tabular}

Table 2. The choice of topics picked by the students

\begin{tabular}{ll}
\hline Topic & number of students \\
\hline Family & 14 \\
A gift & 12 \\
A friend & 11 \\
You & 7 \\
Travel & 3 \\
\hline
\end{tabular}


Table 3. The percentage of students whose performance contained erroneous structures

\begin{tabular}{lll}
\hline & Number of students & Percentage \\
\hline Students who committed no errors & 1 & 2.1 \\
Students who committed less than 5 errors & 6 & 12.7 \\
Students who committed less than 10 errors & 6 & 12.7 \\
Students who committed less than 15 errors & 18 & 38.29 \\
Students who committed 15 errors or more & 16 & 34.04 \\
\hline
\end{tabular}

As can be seen from the statistics the number of students who committed errors is greater than the number of students who produced error free structures. All in all, the performance was as expected as second language learners who have passed the reasonable benchmarks as far as the speaking skill is concerned.

Table 4. The kinds of erroneous structures

\begin{tabular}{ll}
\hline kinds of errors & percentage \\
\hline Grammatical & 45.23 \\
Pronunciation & 33.25 \\
Pragmatic & 12.25 \\
L1 transfer & 9.27 \\
\hline
\end{tabular}

As can be interpreted from the table above, grammar constitutes the bigger hurdle that impedes the learners from producing correct speech. The second noticeable impediment is the production of correct pronunciation of some sounds. However, these hurdles can be eradicated with more emphasis on the listening and the speaking skills.

\section{Conclusion and Recommendations}

The main aim of the paper is to establish the sufficiency of the emphasis of the speaking skill throughout the years of study in the foreign languages department at Taif University. After the test was conducted numbers have shown that the level of the students is within the expected measure as far as the ESL levels are within the benchmarks of the speaking levels. Nonetheless, the room for development still exists within the realm of possible future improvement.

The implications of this study can be suggested in the two areas one is the idea of perceptions and the other is of practice. To solve the problem caused by the lack of emphasis on the teaching of speaking in the department, requirements, there may be the need for curriculum developers to change their perceptions of the importance of the actual teaching of speaking. In teaching practice such that learning the speaking skill becomes the most important goal of a number of the courses closely related to speaking.

Next, we should take account of a way to improve the testing techniques of the speaking skill. In spite of the context-dependent nature of classroom assessment, it is important that a routine test is developed and followed as a part of students' minimum achievement to be passed on to the next level. In this view, improved teacher training courses can work to promote the necessary qualification of teachers as assessors. Developing a reliable test used as a practical testing method used on regular bases is increasingly becoming an imperative requirement as part of quality assurance procedure in most learning institutions.

The research has a number of limitations one of them is that the research was conducted on female students only whereas a complete assessment about the curriculum of the department would be best done for both boys and girls. The second is the number of students contained in the specimen is rather small. This stems from the fact relating to the reserved cultural nature of society as the students were informed that the test will be recorded and only the specified number of students accepted.

\section{References}

Bachman, L. F. (1990). Fundamental considerations in language testing. Oxford: Oxford University Press.

Bardovic-Harling, L. F. (1999). The interlanguage of interlanguage pragmatics: A research Agenda for acquisitional pragmatics. Language Learning, 49, 677-713. http://dx.doi.org/10.1111/0023-8333.00105

Bonk, W. J., \& Ockey, G. J. (2003). A many-facet research analysis of the second language group oral discussion task. Language Testing, 20(1), 89-110. http://dx.doi.org/10.1191/02655322031t245oa

Brown, A. (2000). An investigation of the rating process in the IELTS speaking Module. In R. Tulloh (Ed.), IELTS Research Reports 1996 (Vol. 3, pp. 49-85). Sydney: ELICOS. 
Brown, A. (2003). Interviewer variation and the co-construction of speaking Proficiency. Language Testing, 20(1), 1-25. http://dx.doi.org/10.1191/02655322031t242oa

Brumfit, C. (1984). Communicative methodology in language teaching: the roles of fluency and accuracy. Cambridge: Cambridge University Press.

Burns, A., \& Seidlhofer, B. (2002). Speaking and pronunciation. In N. Schmitt (Ed.), An Introduction to Applied Linguistics. London: Arnold.

Celce-Murcia, M., \& Olshtain, E. (2000). Discourse and context in language teaching. New York: Cambridge University Press.

Ellis, N. (2002). Frequency effects in language processing: a review with implications for theories of implicit and explicit language acquisition. Studies in second language acquisition, 24, 143-188. http://dx.doi.org/10.1017/S0272263102002024

Freed, B. (1995). What makes us think that students who study abroad become fluent? In Freed (Ed.), Second language acquisition in a study abroad context (pp. 123-48). Amsterdam: John Benjamins.

Fulcher, G. (1997). The testing of Speaking in a Second Language. In C. Clapham \& D. Corson (Eds.), Language Testing and Assessment, Vol. 7 of the Encyclopedia of Language Education (pp. 75-85). Dordrecht: Kluwer Academic Publishers.

Fulcher, G., \& Márquez, R. (2003). Task difficulty in speaking tests. Language Testing, 20(3). http://dx.doi.org/10.1191/02655322031t259oa

Hasselgren, A. (1998). Small words and valid testing. PHD thesis. Department of English, Bergen: University of Bergen.

House, J. (1996). Developing pragmatic fluency in English as a foreign language: Routines and Metapragmatics

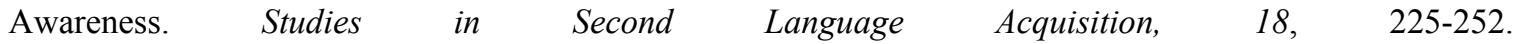
http://dx.doi.org/10.1017/S0272263100014893

Kasper, G. (1996). Introduction: interlanguage pragmatics in SLA. Studies in Second Language Acquisition, 18 , 145-148. http://dx.doi.org/10.1017/S0272263100014856

Kasper, G. (2001). Four perspectives on L2 pragmatic development. Applied Linguistics, 22(4), 502-530. http://dx.doi.org/10.1093/applin/22.4.502

Koponen, M., \& Riggenbach, H. (2000). Overview: Varying perspectives on fluency. In H. Riggenbach (Ed.), Perspectives on fluency (pp. 5-24). Michigan: University of Michigan Press.

Krashen, S. (1984). Immersion, why it works and what it has taught us. Language and Society, 12(1).

Lennon, P. (1990). Investigating fluency in EFL: A quantitative approach. Language Learning, 40, 387-412. http://dx.doi.org/10.1111/j.1467-1770.1990.tb00669.x

Luoma, S. (2004). Assessing speaking. Cambridge: Cambridge University Press. http://dx.doi.org/10.1017/CBO9780511733017

Malvern, D. D., \& Richards, B. J. (1997). A new measure of lexical diversity. In Ryan \& A. Wray (Eds.), Evolving models of language. Clevedon: Multilingual Matters.

McCarthy, M. (1998). Spoken language and applied linguistics. Cambridge: University Press.

McNamara, T. (1096). Measuring second language performance. London: Longman.

Oller, J. W., \& Perkins, K. (1977). Research in language testing. Newbury House publishers, Inc.

Wennerstorm, A. (2000). The role of intonation in second language fluency. In H. Riggenbach (Ed.), Perspectives on fluency (pp. 102-127). Michigan: The University of Michigan Press.

\section{Copyrights}

Copyright for this article is retained by the author(s), with first publication rights granted to the journal.

This is an open-access article distributed under the terms and conditions of the Creative Commons Attribution license (http://creativecommons.org/licenses/by/3.0/). 